\title{
SELEÇÃO DE ALFAFA (MEDICAGO SATIVA L.) PARA TOLERÂNCIA AO ALUMÍNIO EM SOLUÇÃO NUTRITIVA
}

\author{
Karla Médici Saraiva de Ávila*1, Mariana Rockenbach de Ávila, Raquel Schneider-Canny2, Miguel \\ Dall'Agnol $^{1}$, Mêmora Giovana Schmidt de Bitencourt ${ }^{1}$, Gabriela Volkmann ${ }^{1}$
}

\begin{abstract}
RESUMO - A alfafa (Medicago sativa L.) é uma leguminosa com alto potencial produtivo, qualidade de forragem e flexibilidade de utilização. Para a expansão desta forrageira no Brasil, torna-se necessário superar um dos maiores entraves, que é a falta de cultivares adaptadas às nossas condições de baixa fertilidade do solo. $\mathrm{O}$ melhoramento genético de alfafa para tolerância a solos ácidos pode ser uma alternativa importante para a maior utilização desta cultura, contribuindo na produção de carne e leite do país. O objetivo do presente estudo foi selecionar precocemente genótipos de alfafa para tolerância ao alumínio (Al) em solução nutritiva. Foram avaliados nove genótipos (Solo, Solução, Erechim, Porto Alegre, Estrela e São José do Inhacorá) e como testemunha a Cultivar Crioula. As concentrações de Al utilizadas foram:0; 3; 6; 12; $24 ; 48 \mu \mathrm{Mol} \mathrm{L}-$ $1 \mathrm{AlCL}_{3}$ com $100 \mu \mathrm{Mol} \mathrm{L}{ }^{-1}$ de $\mathrm{CaCl}_{2}$ cada. Foram selecionadas 25 plântulas com maior comprimento radicular (cm). Essas plântulas selecionas foram mantidas em casa de vegetação para crescimento e florescimentos. Onde foram realizados cruzamentos controlados dentro de cada genótipo. Com as sementes provenientes destes cruzamentos (F1) foi realizado mais um ciclo de seleção (F2) e os resultados mostraram superioridade do crescimento radicular das populações São José do Inhacorá, Solução e Porto Alegre, indicando uma maior tolerância ao Al tóxico e progresso na seleção para este caráter. Foi possível observar que a seleção em solução nutritiva foi eficiente na discriminação de genótipos com maior tolerância ao alumínio, principalmente nas concentrações $6 \mu \mathrm{Mol} \mathrm{L}{ }^{-1}$ e $12 \mu \mathrm{Mol} \mathrm{L}{ }^{-1}$ de alumínio, com $100 \mu \mathrm{Mol} \mathrm{L-1}$ de cálcio. Os genótipos de alfafa que mostram maior tolerância ao alumínio tóxico (Solução, São José do Inhacorá e Porto Alegre) continuam no Programa de Melhoramento da Universidade Federal do Rio Grande do Sul (UFRGS) para realização de testes de valor, cultivo e uso (VCU) para posteriormente serem encaminhados para registro.
\end{abstract}

Keywords: genetic improvement, forage legume, acidity.

\section{SELECTION OF ALFALFA (MEDICAGO SATIVA L.) FOR TOLERANCE TO ALUMINUM IN NUTRIENT SOLUTION}

\begin{abstract}
Alfalfa (Medicago sativa L.) is a legume with high productive potential, forage quality and flexibility of use. For the greater expansion of this forage in Brazil, is necessary to overcome one of the major obstacles, which is the lack of cultivars adapted to our conditions of low soil fertility. Breeding of alfalfa for tolerance to acid soils may be an important alternative for the greater use of this crop, contributing to the production of meat and milk. The objective of the present study was the selection of alfalfa genotypes for tolerance to aluminum (Al) in nutrient solution. Nine genotypes were evaluated: Cultivar Crioula as a control, Soil, Solução, Erechim, Poa, Estrela and São José do Inhacor., in nutrient solution containing different concentrations of $\mathrm{Al}\left(0,3,6,12,24,24 \mu \mathrm{Mol} \mathrm{L}-1 \mathrm{AlCl}_{3}\right)$ and $100 \mu \mathrm{mol} \mathrm{L-1} \mathrm{CaCl}_{2}$. The root length (CR) was measured and the 25 seedlings with the largest root length were selected. A further selection cycle was carried out and the results showed superiority of the root growth of the SJI, Solução and Poa populations, indicating a greater tolerance to Al toxic and progress in the selection for this character. It is possible to observe that the selectionwas efficient nutrient solution in obtaining materials with greater tolerance to aluminum, mainly in the concentrations 6 $\mu \mathrm{Mol} \mathrm{L} \mathrm{L}^{-1}$ and $12 \mu \mathrm{Mol} \mathrm{L} \mathrm{L}^{-1}$ of aluminum, with 100 ?Mol L-1 of calcium. The alfalfa genotypes showing higher tolerance to aluminum were Solução, São José do Inhacorá (SJI) and Porto Alegre (Poa). In addition, it can be verified that selection in nutrient solution was efficient in increasing the tolerance to Al of alfalfa genotypes.
\end{abstract}

Keywords: by-product, Lactuca sativa L., substrate.

\footnotetext{
${ }^{1}$ Universidade Federal do Rio Grande do Sul, Brasil; ${ }^{2}$ The Samuel Roberts Noble Foundation, Estados Unidos. *E-mail: karlamsaraiva@gmail.com
} 


\section{INTRODUÇÃO}

A alfafa (Medicago sativa L.) é uma leguminosa forrageira, que possui inúmeras características relevantes, como alto potencial produtivo, qualidade de forragem e flexibilidade de utilização e quando bem manejada, é uma cultura capaz de fornecer forragem de qualidade e promover o aumento na produtividade dos rebanhos (Pereira \& Ferreira, 2008). Entretanto, é altamente exigente em termos de fertilidade do solo, exigindo investimentos na correção da acidez e adubação para minimizar os efeitos do alumínio tóxico $\left(\mathrm{Al}^{+3}\right)$ e a baixa disponibilidade de nutrientes. Os solos brasileiros são predominantemente ácidos e com baixa disponibilidade de fósforo (Bahia Filho et al. 1997), o que limita grandemente o desenvolvimento dessa cultura no país. A alfafa é uma planta muito sensível à acidez do solo, por isso em solos com $\mathrm{pH}$ baixo o seu desenvolvimento e produção são muito prejudicados. Em condições de acidez ocorrem alterações no sistema radicular, que começam a apresentar raízes curtas, grossas e bronzeadas e consequentemente diminuição do volume de solo explorado (Moreira et al. 2007). $\mathrm{O} \mathrm{Al}^{+3}$ causa nas plantas, redução e danos ao sistema radicular e em consequência disso, ocorre à deficiência na absorção de água e nutrientes, aumentando o risco de estresse hídrico (Degenhardt et al. 1998). A redução do crescimento da parte aérea ocorre num momento posterior, pois é uma consequência dos danos que ocorrem ao sistema radicular (Matsumoto, 2000).

A redução da quantidade de alumínio no solo pode ser realizada por meio de práticas de calagem, pois este elemento é neutralizado quando o pH do solo é superior a 5,5 (Bohnem et al., 2006). Por outro lado, o uso de corretivos representa acréscimo no custo de produção. Além disso, o alumínio não ocorre apenas na camada arável do solo, mas também em maiores profundidades, tornando difícil a realização esta operação (Souza et al., 2007). Uma alternativa, é a seleção de plantas mais tolerantes ao $\mathrm{Al}^{+3}$ pois o uso de plantas tolerantes pode diminuir os custos de implantação e contribuir para a expansão da alfafa no Brasil.

No melhoramento de plantas para tolerância ao Al, é necessária a adoção de métodos de seleção que simulem o ambiente onde a planta será utilizada, proporcionando também maior controle dos fatores de estresse e facilitando o trabalho de melhoramento (Voight et al., 2004) Dentre muitas técnicas utilizadas para identificar plantas tolerantes ao $\mathrm{Al}^{+3}$, existe o método básico de seleção em solução nutritiva. Esse método tem sido bastante utilizado devido a sua rapidez, facilidade e economia (Janke et al., 2010). Além disso, se baseia na inibição do crescimento radicular, avaliação do acúmulo de $\mathrm{Al}$ nas raízes ou acúmulo de biomassa.

Este estudo tem como objetivo a seleção de r populações de alfafa mais tolerantes ao alumínio, por meio de solução nutritiva.

\section{MATERIALE MÉTODOS}

O experimento foi conduzido em casa-de-vegetação, no período de julho de 2009 a dezembro de 2010. Foram utilizados sete genótipos de alfafa, sendo eles: uma cultivar denominada Crioula (testemunha), quatro populações coletadas no estado do Rio Grande do Sul denominadas Estrela, Erechim, Porto Alegre (Poa) e São José do Inhacorá (SJI). Além de duas populações que já participam do programa de melhoramento de plantas forrageiras da Universidade Federal do Rio Grande do Sul (UFRGS) para tolerância ao Al e são consideradas mais tolerantes ao Al do que a cv. Crioula, sendo elas: Solo (população selecionada em solo ácido) e Solução (população selecionada em solução nutritiva contendo alumínio tóxico).

O trabalho foi composto de duas etapas, sendo que na primeira etapa foi realizado teste de para caracterização dos germoplasmas (populações) e identificação da concentração de $\mathrm{Al}\left(\mathrm{AlCl}_{3}\right)$ em solução nutritiva que melhor discriminasse as populações quanto à tolerância ao Al. Para tanto, foram utilizadas cerca de 0,60 g de sementes de cada uma das sete populações (Crioula, Estrela, Erechim, Poa, SJI, Solo e Solução), previamente escarificadas com lixa ${ }^{\circ} 100$. As sementes foram semeadas em caixas gerbox sobre papel germitest, que foi umedecido desde o primeiro momento com solução nutritiva contendo: $100 \mu \mathrm{Mol} \mathrm{L}^{-1}$ de cálcio $\left(\mathrm{CaCl}_{2} \cdot 2 \mathrm{H}_{2} \mathrm{O}\right)$ e as diferentes concentrações $0,3,6,12$, $24,48 \mu \mathrm{Mol} \mathrm{L}^{-1} \mathrm{de} \mathrm{Al}\left(\mathrm{AlCl}_{3}\right)$. As sementes permaneceram em temperatura ambiente, até a radícula das plântulas de todas as populações apresentarem pelo menos 10 $\mathrm{mm}$. O experimento foi disposto em delineamento fatorial $6 \times 7$ totalizando 42 tratamentos e três repetições.

As plântulas que apresentaram uniformidade e normalidade na formação da radícula foram transferidas para um volume maior de solução, onde se utilizaram telas plásticas fixadas a lâminas de poliestireno expandido 
“isopor”, para a sustentação das plântulas sob a solução nutritiva. A solução nutritiva foi colocada dentro de bandejas plásticas com capacidade de para $5 \mathrm{~L}$ de solução. Ao todo, foram utilizadas doze bandejas plásticas (duas para cada concentração de Al). Cada bandeja continha plântulas das sete populações avaliadas sendo mantidas durante um período de aproximadamente 15 dias. $\mathrm{O}$ pH das soluções foi ajustado para 4,2 e as soluções eram trocadas a cada três dias, visando evitar o acúmulo de exsudatos das raízes e as alterações nas concentrações de $\mathrm{Al}$ e Ca. A solução foi aerada com compressores de ar com uma capacidade de $40 \mathrm{~L} \mathrm{hora}^{-1}$.

Foi avaliado o comprimento radicular (CR) das plântulas de todas as populações nas diferentes concentrações de Al. Os dados foram submetidos à análise estatística com o auxílio do software SAS, pelo procedimento "Factorial ANOVA", constituindo-se de análise de variância fatorial (populações x doses de alumínio), tendo suas médias comparadas pelo teste de Tukey a $5 \%$ de probabilidade.

Após a obtenção dos resultados da primeira etapa, caracterização dos germoplasmas, as populações SJI, Solução e Poa foram consideradas mais tolerantes ao Al tóxico, de acordo com o CR e as concentrações que permitiram uma melhor discriminação dos genótipos foram 6,0 e 12,0 $\mu \mathrm{Mol} \mathrm{L}{ }^{-1}$ de alumínio $\left(\mathrm{AlCl}_{3}\right)$.

Considerando os resultados obtidos na primeira etapa, para a realização da segunda etapa foi utilizada uma concentração intermediária de $8,0 \mu \mathrm{Mol} \mathrm{L}^{-1}$ de $\mathrm{Al}$ $\left(\mathrm{AlCl}_{3}\right)$ e $100 \mu \mathrm{Mol} \mathrm{L}^{-1} \mathrm{de} \mathrm{Ca}\left(\mathrm{CaC}_{2} \cdot 2 \mathrm{H}_{2} \mathrm{O}\right)$ para a seleção das plantas. Nessa fase foi utilizado o mesmo protocolo descrito anteriormente para a caracterização dos germoplasmas selecionados (SJI, Solução e Poa).

Após as plantas serem mantidas em solução nutritiva, foi realizada a seleção dentro de cada uma das três populações, selecionando-se as plântulas que apresentaram o maior CR. A pressão de seleção imposta foi de $10 \%$, sendo selecionadas 25 plântulas por população. Estas foram transplantadas para vasos com substrato comercial e mantidas em casa-de-vegetação até o florescimento.

Foram realizados cruzamentos controlados dentro de cada população por um período de aproximadamente 60 dias. Durante este período a casa-de-vegetação recebeu iluminação artificial com o objetivo de estimular e manter o florescimento das plantas. A iluminação foi realizada com lâmpadas alógenas brancas de $150 \mathrm{~W}$ de potência, que permaneciam ligadas das 6 às 22 horas.

As sementes obtidas através dos cruzamentos realizados constituíram as seguintes populações: Solução $\mathrm{F}_{2}$, São José do Inhacorá $\mathrm{F}_{1}\left(\mathrm{SJI}-\mathrm{F}_{1}\right)$ e Porto Alegre $\mathrm{F}_{1}$ (Poa- $\left.\mathrm{F}_{1}\right)$, as quais passaram por mais um ciclo de seleção utilizando a mesma metodologia descrita anteriormente, visando aumentar a tolerância ao alumínio. Portanto, as sementes obtidas do novo ciclo de seleção foram Solução $\mathrm{F}_{3}$, SJI-F $\mathrm{F}_{2}$ e Poa-F ${ }_{2}$.

Para a avaliação do ganho genético, as populações originais (POA- $F_{1}$, solução $F_{2}, S J I-F_{1}$ ) e as suas progênies (Solução $\mathrm{F}_{3}$, SJI-F e Poa-F $_{2}$ ) foram semeadas em caixas gerbox, com três repetições por população e umedecidas desde o primeiro dia com a solução contendo $8,0 \mu \mathrm{Mol}$ $\mathrm{L}^{-1} \mathrm{de} \mathrm{Al}\left(\mathrm{AlCl}_{3}\right)$ e $100 \mu \mathrm{Mol}{ }^{-} \mathrm{L}^{-1} \mathrm{de} \mathrm{Ca}\left(\mathrm{CaC}_{2} \cdot 2 \mathrm{H}_{2} \mathrm{O}\right)$, repetindo o mesmo protocolo utilizado na caracterização. Foi avaliado o comprimento radicular das plântulas em meio com Al tóxico e os dados foram submetidos à análise de variância para um delineamento fatorial, tendo as médias comparadas pelo teste de Tukey a $5 \%$ de probabilidade.

\section{RESULTADOS E DISCUSSÃO}

Houve interação significativa $(P<0,05)$ entre as populações testadas e as concentrações de $\mathrm{Al}$ utilizadas (Tabela 1). Na ausência de $\mathrm{Al}\left(0 \mu \mathrm{Mol} \mathrm{L}{ }^{-1}\right)$, o maior comprimento radicular, foi da população Solo $\mathrm{F}_{2}$, que não diferiu da população SJI e da PoA. Por outro lado, os menores valores foram das populações Erechim que diferiu de todas as outras, com exceção da Estrela que apresentou um crescimento semelhante.

O método utilizado neste este estudo é baseado no fato de que as plantas são mantidas geralmente, em uma solução ácida contendo Al tóxico, onde é mensurado o comprimento radicular após alguns dias. A tolerância é avaliada pela comparação do comprimento radicular das plantas testadas em relação à testemunha que não recebeu tratamento com Al3+ (Samac \& Tesfaye, 2003).

O método de seleção utilizado neste estudo o qual envolve a utilização de solução nutritiva e avaliação do comprimento radicular foi comprovado em muitos outros estudos para discriminar genótipos tolerantes ao Al, além de avaliar a tolerância em diferentes espécies como Schefer-Basso et al. (2000) em Adesmia spp , 
Tabela 1 - Comprimento radicular médio (cm) de populações de alfafa (Medicago sativa L.) submetidas a diferentes concentrações de alumínio ( $\mu$ Mol L-1) em solução nutritiva

\begin{tabular}{|c|c|c|c|c|c|c|c|}
\hline \multirow{2}{*}{ População } & \multicolumn{7}{|c|}{ Concentrações de $\mathrm{Al}$ ( $\mu$ Mol L-1) } \\
\hline & 0 & 3 & 6 & 12 & 24 & 48 & Médias \\
\hline SJI & A $5,61 \mathrm{ab}$ & A 5,80 a & A 5,63 a & A 5,62 a & B 3,96 a & B 3,62 a & 5,04 \\
\hline Solo F2 & A 5,76 a & B $4,72 \mathrm{~b}$ & C 3,53 cde & D $2,76 \mathrm{~b}$ & $*$ & E 1,67 b & 3,69 \\
\hline Solução F2 & A 4,65 bc & A 4,58 b & A 4,17 bc & B $3,10 \mathrm{~b}$ & BC 2,33 bc & C $2,05 \mathrm{~b}$ & 3,46 \\
\hline Poa & A 4,68 abc & A $4,33 \mathrm{~b}$ & AB $3,7 \mathrm{~cd}$ & BC $2,77 \mathrm{~b}$ & C 2,56 b & C $1,90 \mathrm{~b}$ & 3,32 \\
\hline Crioula (t) & A $4,41 \mathrm{c}$ & A $4,78 \mathrm{~b}$ & B 3,50 cde & BC $3,10 \mathrm{~b}$ & CD 2,25 bc & D $1,63 \mathrm{~b}$ & 3,28 \\
\hline Erechim & A $2,96 \mathrm{~d}$ & A 3,13 c & A 3,20 de & A $2,83 \mathrm{~b}$ & B 1,60 c & B 1,47 b & 2,53 \\
\hline Estrela & A $3,62 \mathrm{~cd}$ & B 2,6 c & B 2,65 e & $*$ & BC 1,97 bc & C $1,46 \mathrm{~b}$ & 2,44 \\
\hline Médias & 4,67 & 4,43 & 3,96 & 3,59 & 2,67 & 1,98 & \\
\hline \% de redução & 0,00 & 5,13 & 15,20 & 23,12 & 42,82 & 57,60 & \\
\hline
\end{tabular}

Médias seguidas de letras maiúsculas iguais na linha, não diferem $(P>0,05)$ pelo teste de Tukey.

Médias seguidas de letras minúsculas iguais na coluna, não diferem $(\mathrm{P}>0,05)$ pelo teste de Tukey.

*Dados faltantes. (t) testemunha.

Crestani et al. (2009) em Avena strigosa Scherb, Peixotto et al. (2007) em Sorghum bicolor e Janke et al. (2010) em Lotus corniculatus $L$., pois sabe-se que o principal alvo da toxidez por alumínio em plântulas é o ápice radicular (Foy et al., 1978), e que a sensibilidade ao Al está intimamente ligada ao crescimento radicular (Samac \& Tesfaye, 2003).

No presente experimento, houve um decréscimo no CR de todas as populações com a adição de Al. $\mathrm{Na}$ concentração de $3 \mu \mathrm{Mol} \mathrm{L}^{-1}$ de $\mathrm{Al}$ o destaque foi a população SJI que diferiu de toas as demais, com um CR de 5,80 cm. As populações Erechim e Estrela novamente foram as que apresentaram os menores CR, enquanto que as demais tiveram um comportamento intermediário e não se diferenciaram. O ápice radicular acumula mais alumínio que outras porções da raiz (Kochian, 1997, Ciamporouvá, 2002). Desta forma, espécies mais tolerantes apresentam maior crescimento radicular que espécies sensíveis na presença do Al. Algumas populações como Crioula, Erechim e SJI, na concentração $3 \mu \mathrm{Mol} \mathrm{L}^{-1} \mathrm{de} \mathrm{Al}$, tiveram um comprimento radicular maior quando comparadas com os comprimentos obtidos em solução nutritiva sem $\mathrm{Al}$, no entanto este aumento não foi estatisticamente significativo.

A quantificação da tolerância ao Al por meio da avaliação do comprimento radicular em soluções nutritivas é simples e muito utilizada devido à facilidade de predição da atividade do $\mathrm{Al}$ (Samac \& Tesfave, 2003).

Na avaliação do comprimento radicular na concentração de $6 \mu \mathrm{Mol} \mathrm{L}{ }^{-1}$ de $\mathrm{Al}$, a maioria das populações apresentaram redução no comprimento radicular, mostrando que houve efeito do $\mathrm{Al}$ sob o desenvolvimento do sistema radicular. Neste nível a população que apresentou o maior comprimento radicular foi novamente a SJI. A população Estrela apresentou o menor comprimento, embora não diferindo das populações Erechim e da cv. Crioula.

É importante ressaltar que as populações Solo e Solução, encontram-se em $\mathrm{F}_{2}$, pois já participam do programa de melhoramento de plantas para tolerância ao Al do Departamento de Plantas Forrageiras e Agrometeorologia da URFGS. Por outro lado, a população SJI é uma população derivada da cv. Crioula que até o momento nunca participou de qualquer processo de seleção, assim como as populações Erechim, Estrela e a Poa.

Na avaliação do CR na concentração $12 \mu \mathrm{Mol} L$ ${ }^{1} \mathrm{de} \mathrm{Al}$ os resultados mostram que o maior comprimento radicular foi mais uma da população SJI, demonstrando o bom desempenho deste germoplasma, seguida de todas as outras populações.

Por outro lado, as concentrações $24 \mu \mathrm{Mol} \mathrm{L}^{-1} \mathrm{e}$ $48 \mu \mathrm{Mol} \mathrm{L}{ }^{-1}$ de $\mathrm{Al}$ foram muito drásticas, impedindo o desenvolvimento das plantas devido aos danos causados ao sistema radicular, com redução do crescimento radicular de todas as populações em aproximadamente 57,6\%. Apesar disso, nessas concentrações a população que apresentou o maior comprimento radicular foi a SJI, mostrando-se superiores as demais. 
Os efeitos da toxidez por Al foram percebidos de maneira proporcional ao aumento das concentrações de Al, ocorrendo uma diminuição do comprimento radicular das populações estudadas. Esses resultados estão de acordo com trabalhos de pesquisa que demonstraram que o crescimento do sistema radicular é a característica mais afetada tanto na susceptibilidade quanto na tolerância aos fatores de acidez do solo (Hartwig et al., 2007).

Os níveis mais baixos não chegam a discriminar os genótipos, enquanto que os mais altos $(24 \mu \mathrm{Mol}$ $\mathrm{L}^{-1}$ e $48 \mu \mathrm{Mol} \mathrm{L}^{-1}$ ) mostram-se bastante drásticos, impedindo o desenvolvimento das plantas. Por outro lado, os níveis intermediários (6 e $12 \mu \mathrm{Mo} \mathrm{L}^{-1} \mathrm{de} \mathrm{Al}$ ) permitiram a melhor discriminação dos genótipos quanto à tolerância ao Al.

As populações SJI, Solução e Poa apresentaram os melhores resultados (Tabela 1), não só em relação ao desempenho do comprimento radicular, mas também por apresentarem uma superioridade em situações de toxidez por Al baixa e moderada. Em função disso, essas populações foram selecionadas para mais ciclos de seleção para tolerância ao $\mathrm{Al}$, cujos resultados são descritos a seguir.

No experimento onde foram comparadas as populações originais e progênies de cada população, observou-se que após no $1^{\circ}$ ciclo de seleção houve diferenças significativas $(p<0,05)$ entre as populações, assim como houve diferenças entre os ciclos de seleção (Figura 1).

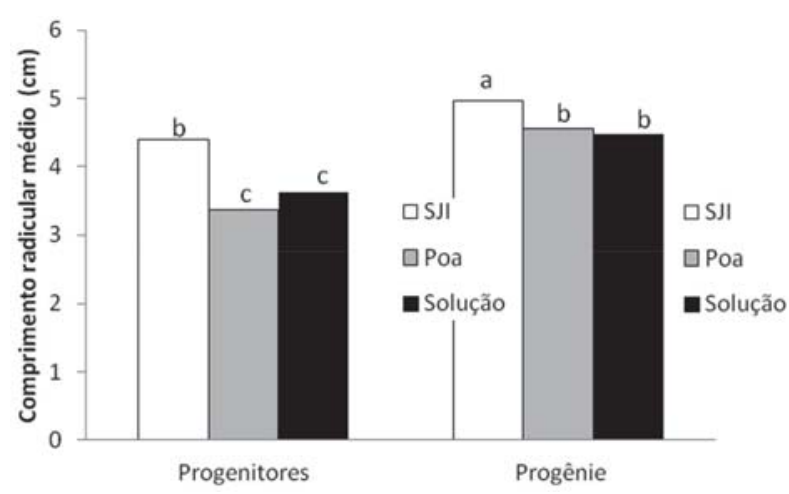

Figura 1- Comprimento radicular de três populações selecionadas para tolerância ao Al em dois ciclos de seleção, sob a concentração de $8 \mu \mathrm{Mol} \mathrm{L-1}$ de Al em solução nutritiva. Médias seguidas de letras minúsculas iguais, não diferem $(\mathrm{P}>0,05)$ pelo teste de Tukey.
Nessa avaliação, a população SJI apresentou o maior CR com média de $4,4 \mathrm{~cm}$ enquanto que as populações Solução e Poa apresentaram 3,6 cm e $3,3 \mathrm{~cm}$, respectivamente, sem diferir estatisticamente. As progênies apresentaram comportamentos semelhantes ao das populações originais, onde a SJI apresentou os maiores comprimentos radiculares em relação à Solução e a Poa, que não diferiram estatisticamente.

Pode-se verificar (Figura 1) que o comprimento radicular das progênies em relação às populações originais aumentou, havendo diferenças significativas $(\mathrm{p}<0,05)$. A população SJI apresentou o maior comprimento radicular tanto em suas plantas originais como em sua progênie com $4,4 \mathrm{~cm}$ e $4,9 \mathrm{~cm}$, respectivamente, havendo um aumento de $11,46 \%$ na progênie.

Na população Poa esse aumento foi de 26,15\%, sendo que os progenitores apresentaram comprimento radicular de 3,3 cm, enquanto que as suas progênies apresentaram em média $4,5 \mathrm{~cm}$. Com relação à população Solução, que já está no terceiro ciclo de seleção, seus progenitores $\left(\mathrm{F}_{2}\right)$ apresentaram comprimento radicular de 3,6 cm e suas progênies $\left(F_{3}\right)$ apresentaram em média $4,4 \mathrm{~cm}$, tendo um aumento de $18,97 \%$ do comprimento radicular.

A maior porcentagem do aumento do comprimento radicular foi da população Poa (26,15\%), provavelmente devido ao fato desta população nunca haver sofrido qualquer processo de seleção. Em geral, o que se espera de um material nunca melhorado anteriormente é um maior ganho nos primeiros ciclos de seleção, que pode ser explicado pela maior variabilidade existente em germoplasmas do tipo Crioulo (Carvalho et al., 2008). Já a população Solução teve um aumento intermediário no percentual no comprimento radicular (18,97\%), provavelmente porque ao longo das etapas de seleção, a variabilidade foi sendo reduzida e, desta maneira, torna-se mais difícil de ser explorada (Carvalho et al., 2008).

As progênies da população SJI apresentaram a menor porcentagem de incremento do comprimento radicular em relação às demais populações $(11,46 \%)$. Embora seja um germoplasma derivado da cv. Crioula, ou seja, não sofreu nenhum processo de seleção, o solo da região onde foi coletada, pode apresentar altos teores de $\mathrm{Al}$ e provavelmente isso tenha contribuído para um processo de seleção natural do material. 
Essas respostas demonstraram que houve progresso em termos de tolerância, principalmente quando se avaliam os diversos fatores que envolvem esta característica em alfafa. Entre esses fatores envolvidos pode-se citar a alta sensibilidade da alfafa ao Al tóxico (Blamey et al., 1990, Caetano et al., 2002) e também as características genéticas da planta, que é autotetraplóide, o que possibilita segregações complexas de alelos num locus simples, dificultando a herança de características com mais de um gene (Fehr, 1987; Junior, 2001; Correa et al., 2003), além da condição alógama, que é outra dificuldade que se apresenta na fixação de características agronômicas.

\section{CONCLUSÃO}

A utilização de cultivares capazes de tolerar solos ácidos, com menores adições de calcário, apresentase como uma alternativa economicamente sustentável. O maior comprimento radicular observado nas plantas tolerantes ao $\mathrm{Al}$ permite a maior possibilidade de absorção dos nutrientes além da camada arável e, também o acesso a água nas camadas mais profundas, durante o período de déficit hídrico. Além disso, ainda torna possível a redução dos gastos relacionados à correção do solo, durante a implantação e/ou manutenção da pastagem.

Apesar disso, esses materiais ainda devem ser testados em condições de campo, visando um conhecimento do comportamento das populações tolerantes em condições reais de utilização.

Contudo pode-se observar que a seleção em solução nutritiva foi eficiente na obtenção de materiais com maior tolerância ao alumínio, principalmente nas concentrações $6 \mu \mathrm{Mol} \mathrm{L}{ }^{-1}$ e $12 \mu \mathrm{Mol} \mathrm{L}{ }^{-1}$ de alumínio, com $100 \mu \mathrm{Mol}$ $\mathrm{L}^{-1}$ de cálcio. Os genótipos de alfafa que mostram maior tolerância ao alumínio foram Solução, São José do Inhacorá (SJI) e Porto Alegre (Poa). Além disso, pode-se verificar que a seleção em solução nutritiva foi eficiente em aumentar a tolerância ao Al dos genótipos de alfafa.

\section{LITERATURACITADA}

BAHIA FILHO, A.F.C.; MAGNAVACA, R.; SCHAFFERT, R.E. Identification, utilization and economic impact of maize germplasm tolerant to low levels of phosphorus and toxic levels of exchangeable aluminum in Brazilian soils. In:

Plant soil interaction at low pH: sustainable agriculture and forestry production. Belo Horizonte-MG, p.59-72, 1997.
BOHNEM, H.; MEURER, E.J.; BISSANI, C.A. Solos ácidos e solos afetados por sais. In: MEURER, E.J. (Ed) Fundamentos de química do solo. 3.ed. Porto Alegre, Genesis, 2006. p.163-180.

CARVALHO, F.I.F.; LORENCETTI, C.; MARCHIORO, V.S.; SILVA, S.A. Condução de populações no melhoramento genético de plantas. Pelotas, RS, Editora Universitária, 2.ed. 2008. p.288.

CIAMPOROUÁ, M. Morphological and structural responses of plant roots to aluminum at organ, tissue, and cellular levels. Biologia

Plantarum, v.45, p.161-171, 2002.

CORREA, A.M.; GONÇALVES, M.C.; DESTRO, D. et al. Estimates of genetic parameters in common bean genotypes. Crop Breeding and Applied Biotechonology, v.3, p.23-230, 2003.

CRESTANI, M.; CARVALHO, F.I.F.; OLIVEIRA, A.C. et al. Estresse por alumínio em genótipos de aveia preta em condição hidropônica.

Bragantia, Campinas, v.68, n.3, p.639-649, 2009.

DEGENHARDT, J.; LARSEN, P.B.; HOWELL, S.H.; KOCHIAN, L.V. Aluminum resistance in the Arabidopsis mutant alr-104 is caused by an aluminum-induced increase in rhizosphere $\mathrm{pH}$. Plant Physiology, Rockville, v.117, n.1, p.19271998.

FEHR, W.R. Principles of cultivar development. New York: McGraw-Hill, v.l. p.536, 1998.

FOY, C.D.; CHANEY, R.L.; WHITE, M.C. The physiology of metal toxicity in plants. Annual Review of Plant Physiology, Palo Alto, v.29, p.511-566, 1978.

HARTWIG, I.; OLIVEIRA, A.C.; CARVALHO, F.I.F. et al. Mecanismos associados à tolerância ao alumínio em plantas. Semina: Ciencias Agrárias, Londrina, v.28, n.2, p.219-228, 2007.

HOWELER, R.H.; CAVADID, L.F. Screening of rice cultivars for tolerance to Al-toxicity in nutrients solutions as compared with a field screening method. Agronomy Journal, v.68, p.551-555, 1976. 
JANKE A.; DALL’AGNOL, M.; SANTOS, A.M.; BISSANI, C.A. seleção de populações de Lotus Cornuculatus L. com maior tolerância ao alumínio em solução nutritiva. Revista Brasileira de Zootecnia, v.39, n.11, p.2366-2370, 2010.

KOCHIAN, L.V.; JONES, D.L. Aluminum toxicity and resistance in plants. In: YOKEL, R.; GOLUB, M.S. Research issues in aluminum toxicity. Bristol: Taylor and Francis Publishers, 1997. p.69-90.

MATSUMOTO, H. Cell biology of aluminum toxicity and tolerance in higher plants.

International Review Cytology, San Diego, v.200, p.1-46, 2000.

MOREIRA, A.; BERNARDI, A.C.C.; RASSINI, J.B. et al. Fertilidade do solo e estado nutricional da alfafa cultivada nos trópicos. São Carlos: Embrapa Pecuária Sudeste, 2007. 40p. Disponível em: http:// www.cppse.embrapa.br/servicos/ publicacaogratuita/documentos/ Documentos67.pdf/view $<$ Acesso em 24 de novembro de 2010.

PEIXOTO, P.H.P.; PIMENTA, D.S.; CAMBRAIA, J. Alterações morfológicas e acúmulo de compostos fenólicos em plantas de sorgo sob estresse de alumínio. Bragantia, Campinas, v.66, n.1, p.1725, 2007.

PEREIRA, A.V.; FERREIRA, R.P. Cultivares de alfafa. In: FERREIRA, R.P.; RASSINI, J.B.; RODRIGUES, A.A. et al. (Eds.) Cultivo e utilização da alfafa nos trópicos. São Carlos, Embrapa Pecuária Sudeste. 2008. p.193214.
ROCHA, W.S.D.; MARTINS, C.E.; SOUZA SOBRINHO, F. et al. Tolerância de genótipos de alfafa ao alumínio em solução. XXXI CONGRESSO BRASILEIRO DE CIÊNCIA DO SOLO. GramadoRS, 2007.

SAMAC, D.A.; TESFAYE, M. Plant improvement for tolerance to aluminum in acid soils. Plant Cell, v.75, p.189-207, 2003.

SANTOS A.M.; DALL'AGNOL M.; JANKE A. et al. Caracterização de espécies diploides de Lotus em resposta a toxidez por alumínio. Revista Brasileira de Zootecnia, v.40, n.5, p.978984, 2011.

SCHEFFER-BASSO, S.M.; DALL'AGNOL, M.; CAETANO, J.H.S. et al. Crescimento de plântulas de Adesmia spp. submetidas a doses de alumínio em solução nutritiva. Ciência Rural, Santa Maria, v.30, n.2, p.217-222, 2000.

SOUSA, D.M.G.; MIRANDA, L.N.; OLIVEIRA, S.A. Acidez do solo e sua correção. In: NOVAIS, R.F.; ALVAREZ, V.H.; BARROS, N.F. et al. (Eds.) Fertilidade do solo. Viçosa-MG: Sociedade Brasileira de Ciência do Solo, 2007. p. 205-274.

SOUZA JÚNIOR, C.L. Melhoramento de espécies alógamas. In: NASS, L.L.; VALOIS, A.C.C.; MELO, I.S. et al. (Eds) Recursos genéticos e melhoramento: plantas. Rondonópolis: Fundação MT, 2001. p.159-199.

VOIGT, P.W.; STALEY, T.E. Selection for aluminum and acidsoil resistance in White clover. Crop Science, v.44, p.38-48, 2004.

Recebido para publicação em 15/1/2019 e aprovado em 25/3/2019. 